\title{
Experiments in rheoplasis during sediment intrusion
}

\author{
A.G. Plint ${ }^{l}, H . W$. van de Poll ${ }^{l}$ and I.M. Patel ${ }^{2}$ \\ ${ }^{1}$ Department of Geology, University of New Brunswick, \\ Fredericton, New Brunswick, Canada E3B $5 A 3$ \\ ${ }^{2}$ Department of Geology, University of New Brunswick, \\ Saint John, New Brunswick, Canada E3L $4 L 5$
}

\begin{abstract}
Injection of semi-fluid silt/water suspensions into semi-fluld sand/cement slurries resulted in the formation of a variety of structures at the interface between the two materials. These structures resemble flute, load, groove and ridge-casts and form as a result of flow-moulding ('rheoplasis'). These experimental results complement earlier work on certain natural occurrences of these structures and substantiate the hypothesis that they form as a result of postdepositional sediment movement and not through primary sedimentary processes.

L'Injection de suspensions aqueuses semi-fluides de limon dans des mélanges semi-fluides de sable et de clment a produit une variété de formes à la surface de contact des deux matériaux. Ces formes, qui ressemblent aux empreintes de charge, flûtes, cannelures et crêtes, résultent du moulage d'une coulée ('rhéoplasie'). Les résultats de ces expériences complémentent des travaux antérieurs qui traitent d'exemples naturels de ces formes et appuient l'hypothèse selon laquelle ces formes résultent du mouvement des sédiments après leur déposition et non pas de processus sédimentaires primaires.
\end{abstract}

[Traduit par le journal]

\section{INTRODUCTION}

In a recent paper, Poll \& Patel (1981) described a variety of sedimentary structures, resembling load, flute and groove casts. These structures, morphologically indistinguishable from sole markings of primary origin, differ from the latter in that they occur at the interface between sandstone and discrete masses of siltstone. The sole-mark-like structures comprise inward-protruding bulges of sandstone into siltstone and occur on all sides of the siltstone masses (including 'bottom' surfaces) and are at all orientations to bedding. Field evidence shows clearly that both the sandstone and siltstone have suffered substantial post-depositional remobilization which probably reflects an initial inverse density stratifaction. Under these conditions there exists considerable potential energy (Anketell 1968; Anketell et al. 1970). As a result of induced shear, perhaps due to earthquakes, major remobilization of the sediment may occur. Ascending, relatively less dense mud bodies may remain attached to the parent bed forming diapirs, or may become completely detached 'intrusions'. The field evidence suggests that the flutes, grooves, etc. formed through a process of flowmoulding ('rheoplasis') at the sand-silt interface during periods of sub-surface remobilization when siltstone masses were intruded into adjacent liquefied sandstone (Po11 \& Pate1, 1981). In order to test this hypothesis, a series of experiments were conducted in an attempt to replicate natural rheoplastic structures. The experimental results showed that, in almost all instances, inward-protruding bulges of cement into mud formed at the mud-cement interface. We believe this fact to be important substantive evidence in favour of the process of rheoplasis.

This paper describes the experimental technique and includes a preliminary account of the results of the first series of experiments.

\section{METHODS}

\section{General}

The experiments in rheoplasis involved injecting mud of varying consistency, into a box containing a sand/cement slurry, again of varying consistency. Following mud injection, the cement was allowed to set, removed from the box and sectioned. The mud could then be washed out and the mud-cement interface examined. 


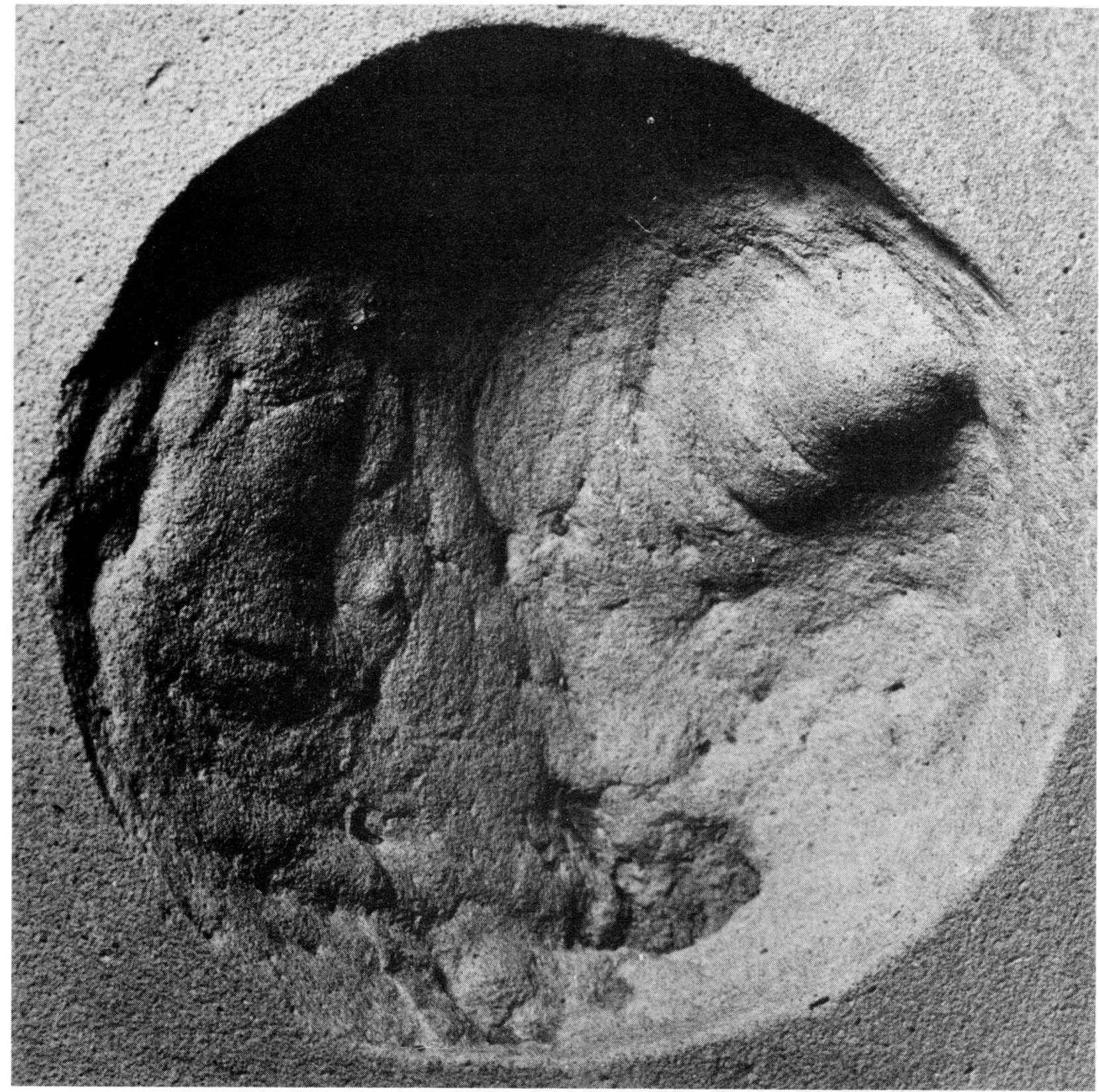

\section{$10 \mathrm{cms}$}

Fig. 1 - Photograph of the roof of a cavity formed by the injection ('intrusion') of soft silt into semi-fluid cement. (The picture shows the cavity after the silt had been washed away). Of particular interest is the relatively large protrusion of cement into the cavity*. This structure clearly demonstrates that inward-protruding bulges do indeed form during sediment intrusion. Note also the faint striations (skin-friction lines) on the surface of the cavity which indicate the direction of mud flow during intrusion.

*Note - Some viewers may see this structure as an upstanding 'hemisphere' with a 'depression' in the upper-right quadrant. A little practice, perhaps with rotation of the photograph should result in the correct impression. 

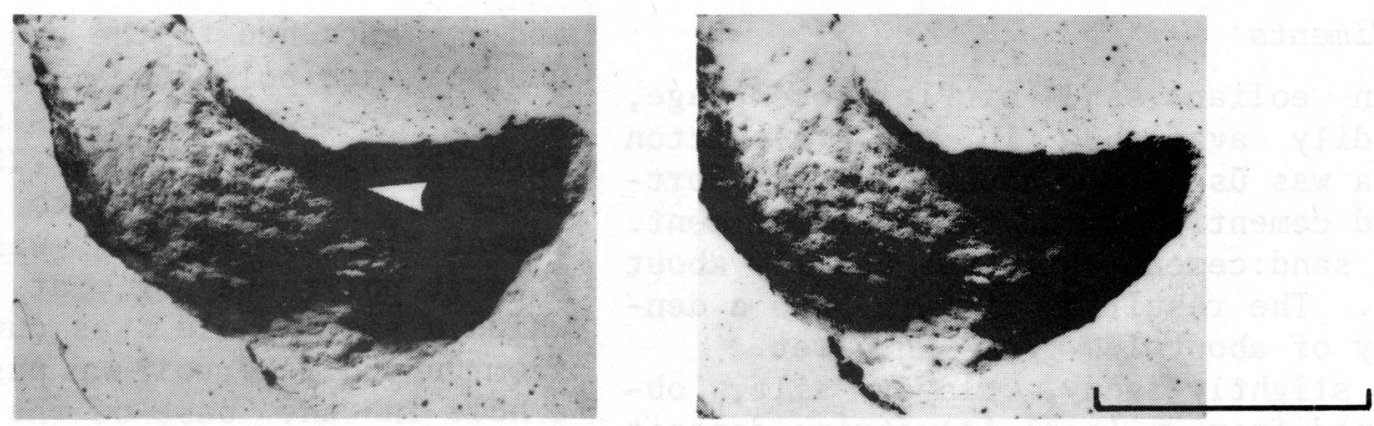

Fig. 2 - (Stereopair). Elongate, oriented rheoplastic structures, resembling flutes, formed on the walls of an experimental mud intrusion. Mud was intruded from below and flowed up through the cement slurry, emerging at the surface at the top left. Arrow shows flow direction.
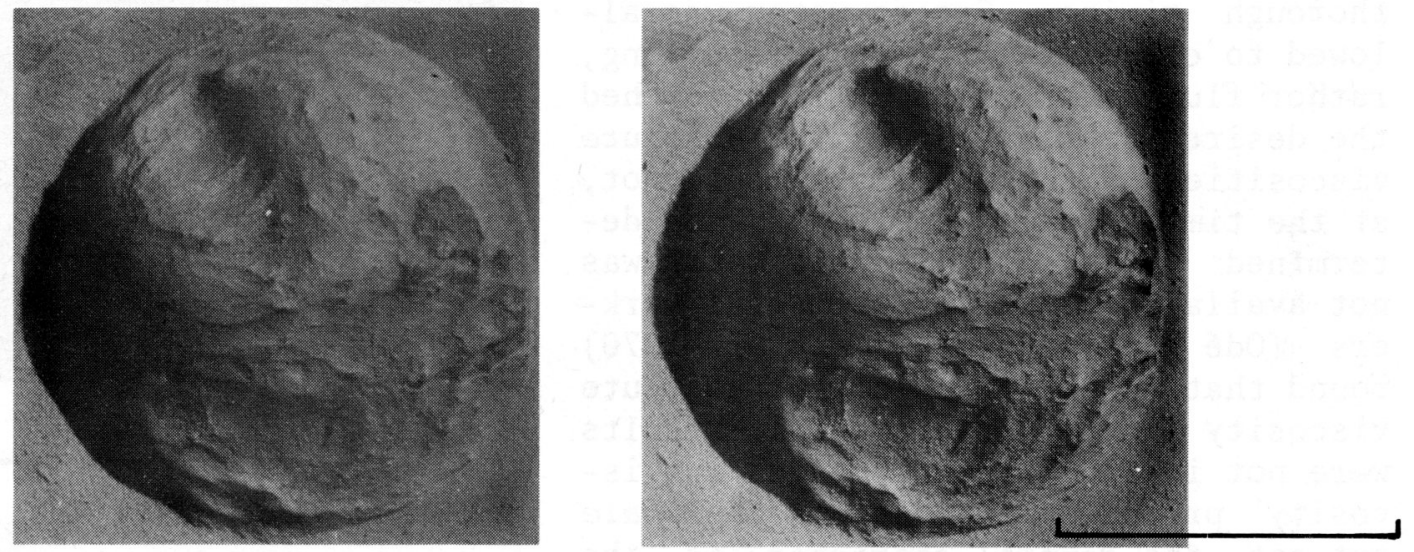

Fig. 3 - (Stereopair). Large, isolated, flute-like rheoplastic structure on the roof of an experimental mud intrusion. Note the marked asymmetry of the rheoplast.
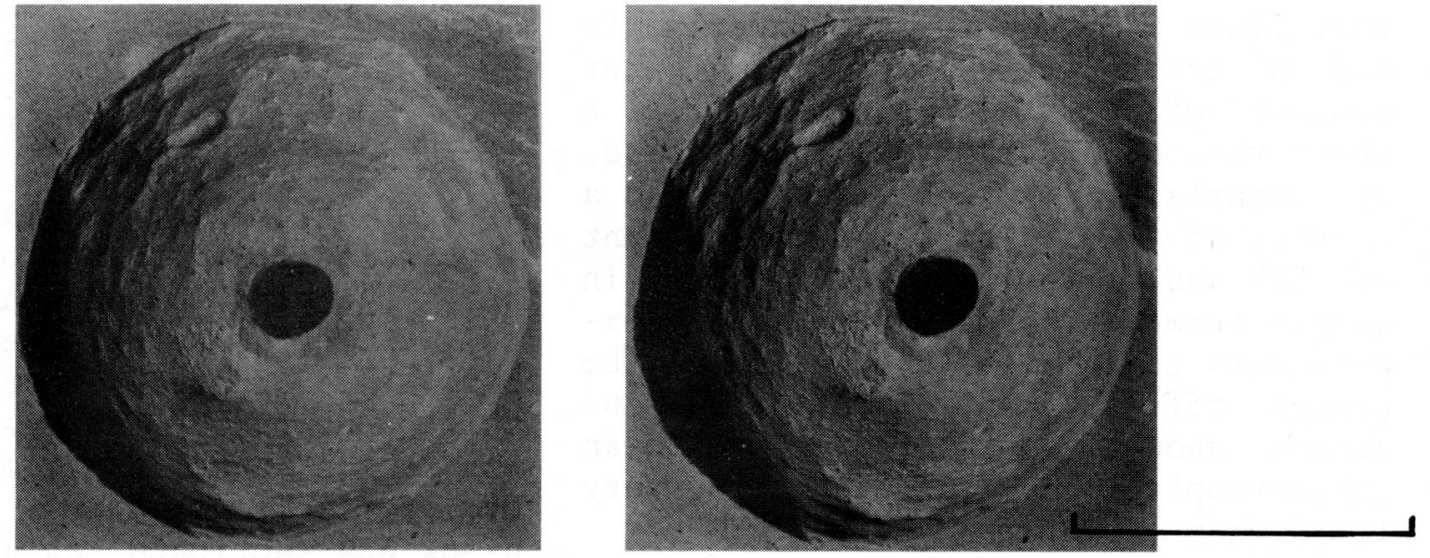

Fig. 4 - (Stereopair). Smal1, isolated rheoplastic structures on the flanks of an experimental mud intrusion. Mud was intruded through the hole at the bottom. (Figs. 2 and 4 are, respectively, upper and lower halves of the same block). 


\section{Sediments}

An eolian sand of Pleistocene age, readily available in the Fredericton area was used in conjunction with Portland cement to form the host sediment. The sand:cement ratio was usually about $3: 1$. The resulting mixture had a density of about $1.9 \mathrm{~g} / \mathrm{cm}^{3}$ when wet.

A slightly sandy, clayey silt, obtained from a local lacustrine deposit of Pleistocene age was used for injection. It was allowed to dry thoroughly at room temperature, then powdered using pestle and mortar. From this, a mudwater suspension was prepared, using an electric mixer to achieve quick and thorough mixing. Excess water was allowed to evaporate from the resulting, rather fluid suspension until it reached the desired consistency. The absolute viscosities of the materials could not, at the time of the experiments, be determined as a suitable viscometer was not available. Other experimental workers (Odé 1966; Anketell et al. 1970) found that, despite the lack of absolute viscosity data, experimental results were not invalidated as changes in viscosity produced changes in the scale but not the general character of the deformational structures. In view of this, we feel that our results remain valid. A rotary viscometer subsequently became available, enabling us to determine the broad range of mud viscosities used in the injection experiments. The most fluid mud used in the experiments had a density of $\simeq 1.59 \mathrm{~g} / \mathrm{cm}^{3}$, a water content of $\simeq 64 \%$ and viscosity (at a shear rate of $5.64 \mathrm{~cm} / \mathrm{sec}$ ) of 160 poise. By comparison, the stiffest mud had a density of $\simeq 1.67 \mathrm{~g} / \mathrm{cm}^{3}$, a water content of $\simeq 57 \%$ and viscosity of $\simeq 400$ poise. In simple terms, the mud used in the experiments could, in general, barely be poured off a spoon. Both the mud and cement showed extreme non-Newtonian (thixotropic) behaviour, becoming very fluid when stirred.

\section{Procedure}

A stout polythene bag of about $4 \ell$ capacity was used as a mud reservoir, and was attached to the end of a threequarter inch polythene pipe with a hoseclamp. A rectangular, slightly downward-tapering wooden box $(25 \mathrm{~cm}$ square, $40 \mathrm{~cm} \mathrm{high)} \mathrm{was} \mathrm{used} \mathrm{to} \mathrm{contain} \mathrm{the}$ cement slurry. The box was lined with a large polythene bag, at the base of which a small hole was cut. The pipe from the mud reservoir was passed through a hole in the base of the box and attached to the polythene liner with another hose clamp. The box was then
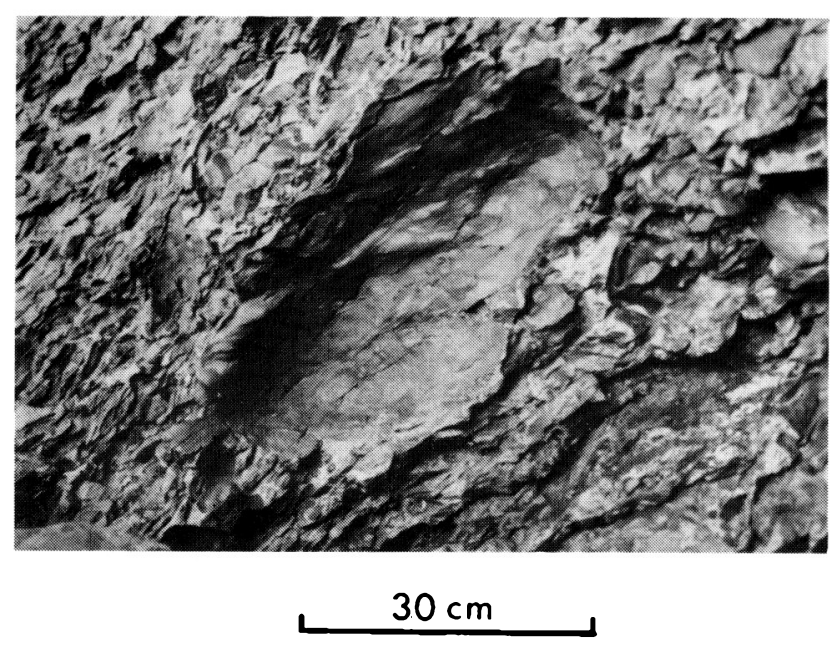

Fig. 5 - Part of the roof of a natural mud intrusion (Boss Point Formation, Johnson Mills, N.B.), showing isolated, flute-like rheoplastic structures, comparable to those shown in Figs. 1-4.

filled with cement slurry. Firm hand pressure was applied to the mud bag, causing mud to be intruded into the cement. Following mud intrusion, the lower end of the pipe was clamped to prevent back-flow of mud, and the cement was allowed to set overnight. Once set, the pipe was disconnected and the cement block carefully removed from the box, the tapered shape facilitating this operation. The polythene liner was removed and the cement allowed to dry for several hours. When dry, the block was sectioned on a large diamond saw and the mud carefully washed out of the interior. Any structures formed at the mud/cement interface were then clearly visible. 
Results

Virtually all experiments yielded inward protruding structures comparable in form to those found in natural examples of mud intrusion (Fig. 1). Representative examples of the results are illustrated below.

\section{Flutes}

Various flute-like structures formed over quite a wide range of viscosities; the best examples formed where cement and mud were of approximately similar viscosities. If the mud intrusion broke through to the surface of the cement, relatively rapid flow ensued. Resultant flute-markings were elongate parallel to the flow direction (Fig. 2). In another experiment, isolated, both relatively large and small flute-like structures developed on the roof and sides of the mud intrusion (Figs. 1, 3 and 4 cf. fig. 5 and figs. 11 and 12 in Poll and Patel, 1981).

\section{Grooves}

Grooves formed less commonly than flutes, the best example is shown in
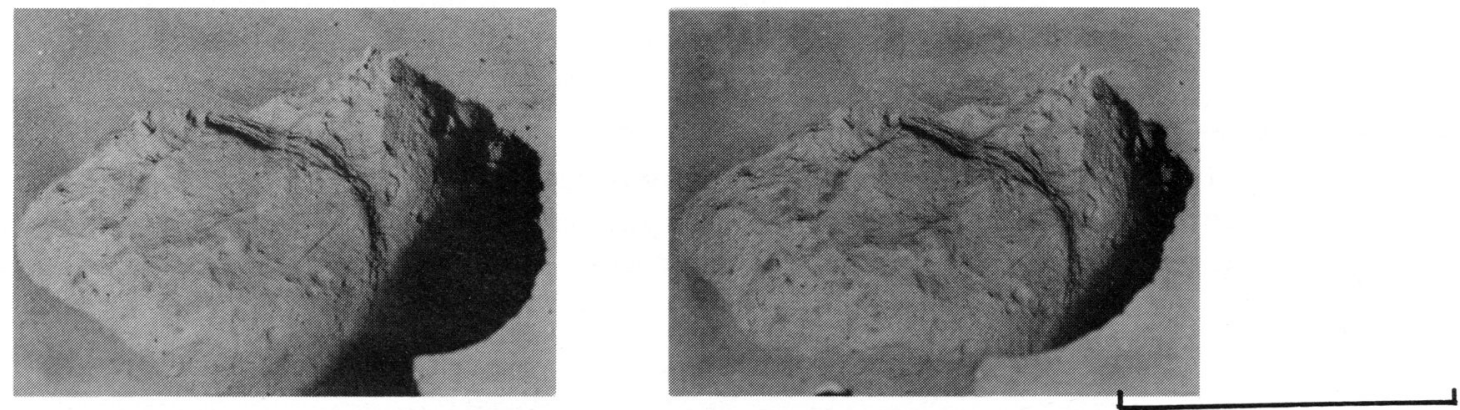

Fig. 6 - (Stereopair). Striated groove cast on the roof of an experimental mud intrusion.
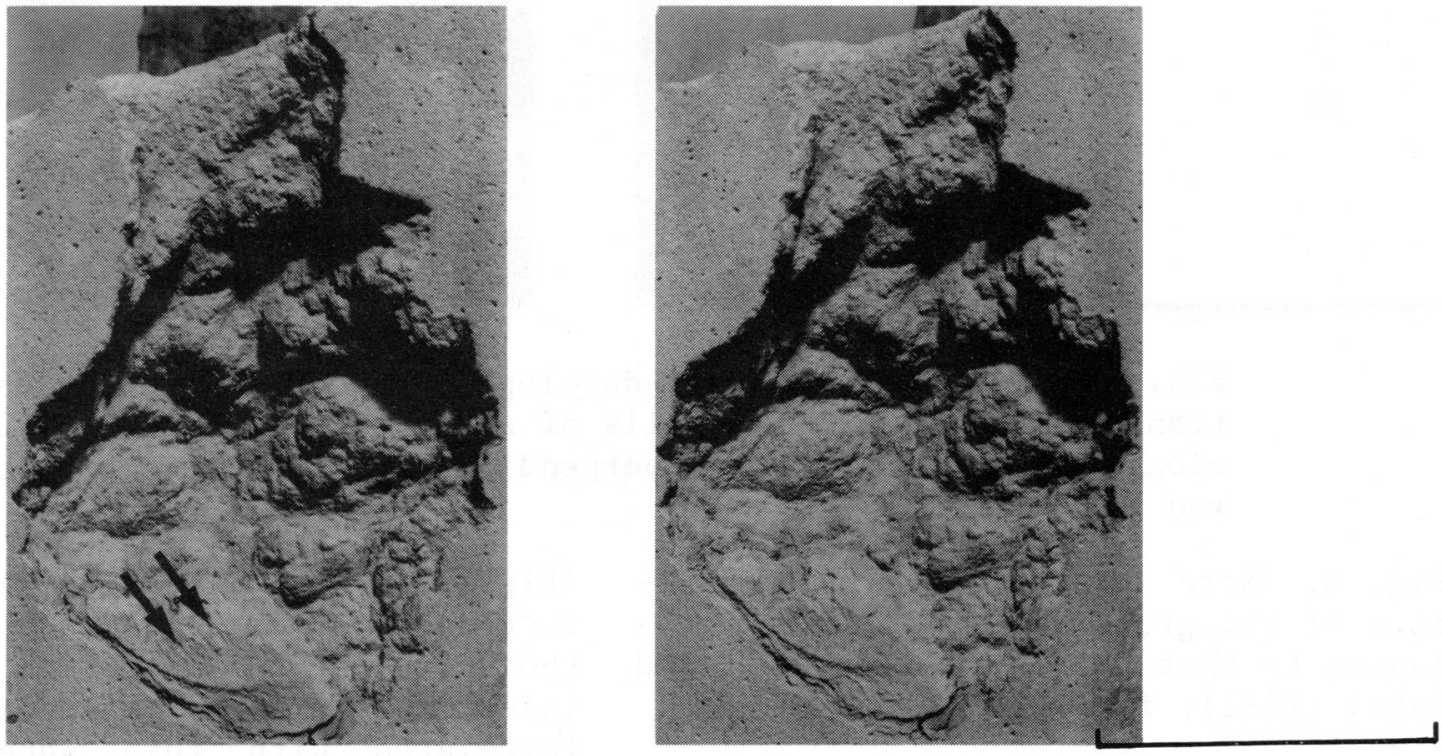

Fig. 7 - (Stereopair). Inward-bulging load-structures on the walls of an experimental mud intrusion. A mass of cement, intercalated with mud laminae (arrowed) probably formed by repeated slumping of cement from the walls during mud intrusion. 

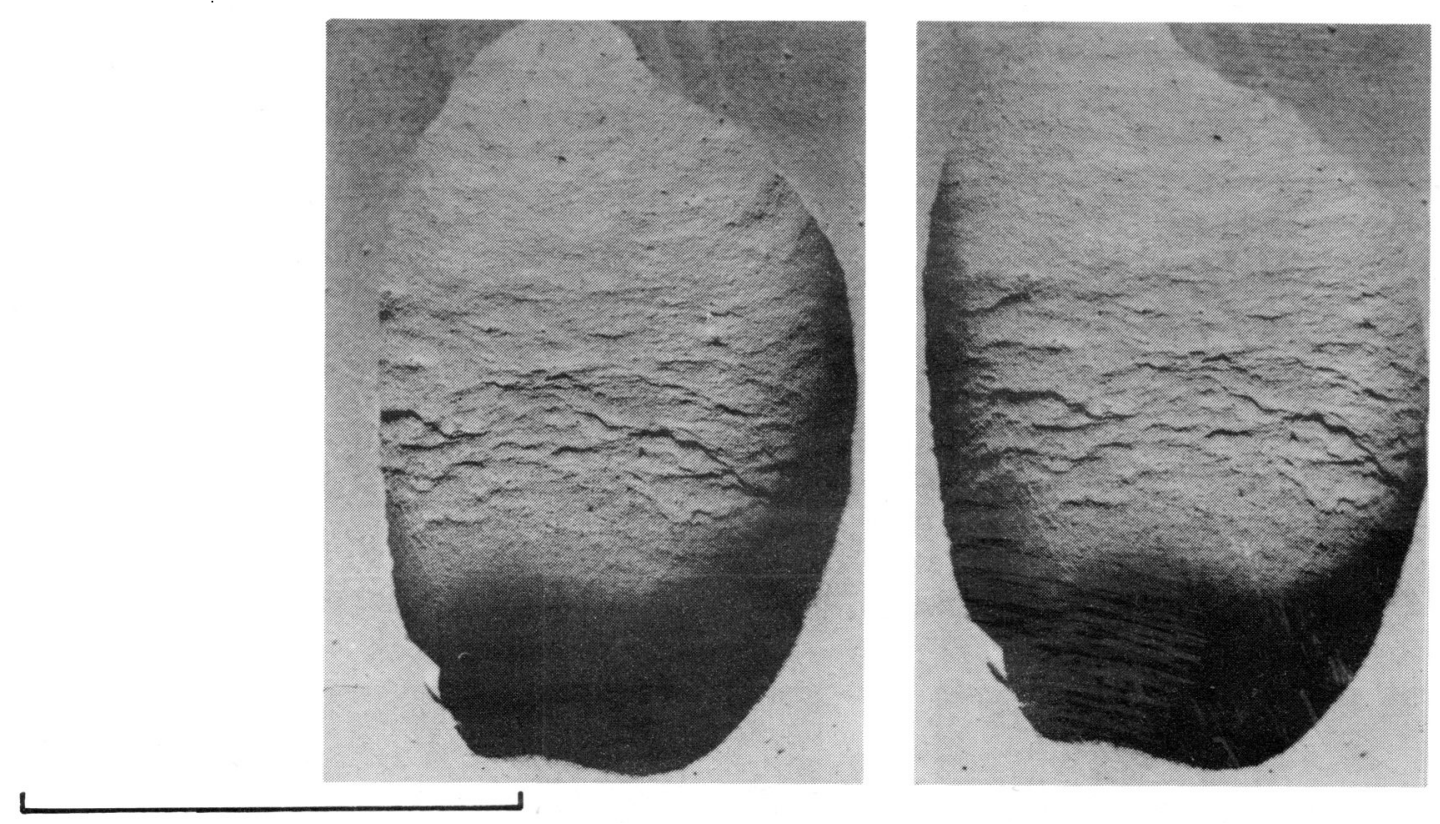

Fig. 8 - (Stereopair). Transverse ridges, about $1 \mathrm{~mm}$ high, formed on the walls of an experimental mud intrusion. Ridges are oriented perpendicular to the direction of mud intrusion.
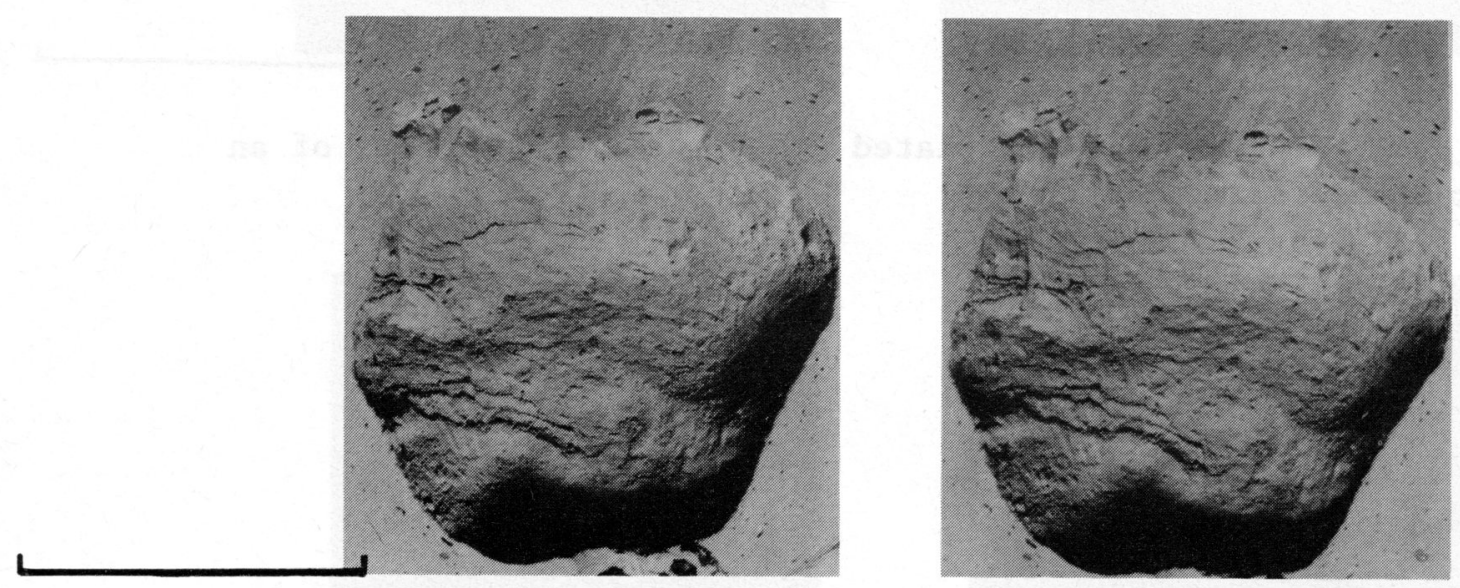

Fig. 9 - (stereopair). We11-developed, strongly asymmetrical transverse ridges on the walls of an experimental mud intrusion. Ridges are oriented perpendicular to the direction of mud intrusion.

Fig. 6. Note the finely striated surface of the groove-cast, precisely analagous to that illustrated by Pol1 and Patel (1981), fig. 17.

\section{Load Structures}

When both mud and cement slurry were relatively fluid, structures resembling load casts developed, giving a 'quilted' appearance to the mud-cement interface
(Fig. 7). In the example illustrated, successive layers of cement flowed into the bottom of the intrusion during mud injection, forming a mass of cement intercalated with thin sheets of mud (arrowed in Fig. 7, lower part of cavity).

\section{Transverse Ridges}

Small-scale ( $\leq 1 \mathrm{~mm}$ high) asymmetric step-like ridges formed in several ex- 


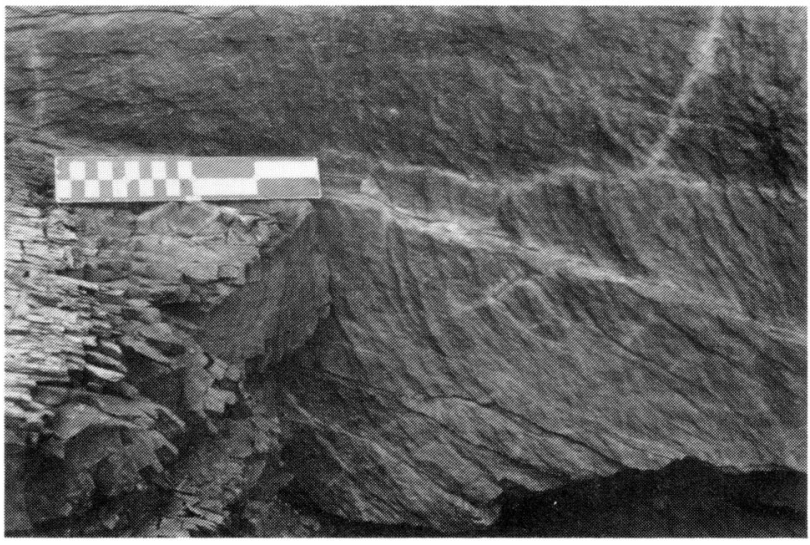

Fig. 10 - Natural example of transverse ridges (Boss Point Formation, Cape Enrage, N.B.). The scale bar $(20 \mathrm{cms})$ lies on a mass of grey siltstone that has been intruded into the sandstone. The differential movement of the two materials is revealed by the transverse ridges on the plane of contact.

periments where mud viscosity exceeded that of the cement by at least $2.5: 1$. These features (Figs. 8, 9) are identical to those found in nature (Fig. 10 cf. fig. 18, Poll and Patel 1981). Ridges formed transverse to the direction of mud flow and were presumably the result of drag exerted by the mud on the cement.

\section{DISCUSSION}

\section{Experimental Mud Intrusion}

In view of these experimental results, it is suggested that the process of rheoplasis (flow-moulding) is capable of producing a variety of structures resembling sole marks at the interface between semi-fluid mud and a sand/cement slurry. The experiments show that, except where the water content is very high (mud containing $>\simeq 65 \%$ water/vol.) the mud and cement slurry behaved essentially as two immiscible fluids.

The precise mechanism by which the rheoplastic structures form is, as yet, not entirely clear and is the subject of further investigation. However, it seems likely that differential viscosity, density and movement are the most important factors involved. It is evident, even from this initial series of experiments, that the differential viscosities of the two materials have an important influence upon the type of rheoplastic structures that form during mud intrusion. It also seems likely that the rate at which mud is intruded will influence the type and shape of structures.

\section{Natural Mud Intrusion}

Natural mud intrusions, up to several metres in diameter occur widely in the Carboniferous and Lower Permian sediments of the Maritime Provinces (Poll and Patel 1980; Poll and Patel 1981; Plint and Poll 1982; Poll et al. 1982). These mud intrusions may be attached to their parent bed as diapirs, or may be completely detached. In both cases, the walls of the mud intrusions are usually ornamented with a variety of rheoplastic structures (Fig. 11). Where intrusions have become detached, their 'intrusion pathways' through the enclosing sandstone are marked by thin films of mud, lining fracture-like separation surfaces which cross-cut bedding (Poll and Patel

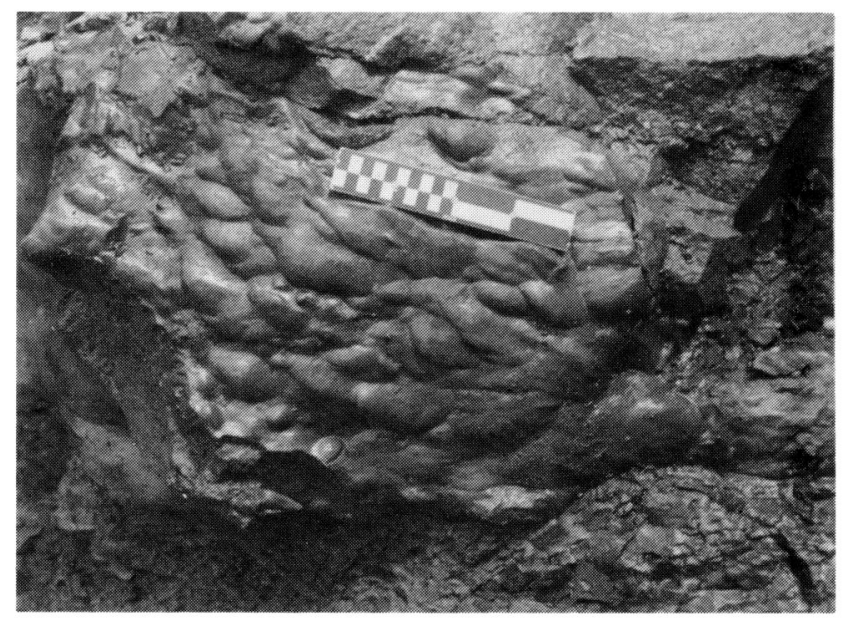

Fig. 11 - Flute-like rheoplastic structures (preserved as casts in sandstone) on the walls of a large natural silt intrusion; Cumberland Group, Apple Head, N.S. Bedding dips 'into' the photograph at $\cong 10^{\circ}$. The fluted margin of the intrusion is approximately normal to bedding near the scale bar, but turns parallel to bedding below and above the scale. 
1981). In view of this evidence, these mud bodies cannot reasonably be interpreted as sedimentary clasts.

The field relations, viewed in conjunction with our experimental results are seen as confirmation of the reality and importance of rheoplasis as a process capable of generating structures, closely resembling. sole markings, during post-depositional sediment movement. Sediment remobilization and intrusion probably took place while in a liquefied state; a condition that was almost certainly the result of earthquake shock (Tuthill and Laird 1966). Dramatic demonstrations of sediment remobilization have been afforded by recent large earthquakes eg. Alaska, 1964 (Hansen 1965; Tuthill and Laird 1966; Waller 1968) and Niigata 1964 (Kawasumi 1968) when large volumes of sand and mud were ejected at the ground surface, accompanied by localized subsidence features. Clearly, these spectacular phenomena are evidence of major subsurface sediment movement, much of which probably has no surface expression (Reimnitz and Marshall 1965).

Although water is of prime importance in the liquefaction of sediment, the presence of gases, principally methane can make an important contribution to spontaneous liquefaction. In the Carboniferous of southern New Brunswick, zones of mud intrusion ('brecciforms' of Poll and Patel 1981) commonly contain large quantities of plant debris. It is possible that the decay of this organic matter during early burial diagenesis generated quantities of methane which dissolved under pressure in the pore water. As the result of a sudden fall in pore pressure, eg. due to seismic shock, bubbles of gas could form, separate the grains and reduce the strength of the sediment to that of a fluid (Monroe 1969 and cf. Byerly 1942, p. 68). In this state, movement of the sediment in response to unstable pressure and density gradients could easily have occurred (cf. Tuthill and Laird 1966).

\section{CONCLUSIONS}

Experiments show that when semi-fluid mud is intruded into a sand-cement slurry a variety of structures, resembling sole markings form at the interface between the two materials through the process of rheoplasis (flow-moulding). Although the exact nature of this process is still unclear, it seems likely that differential viscosity, density and movement at the mud/cement interface are important factors.

In the Carboniferous and Lower Permian of the Maritime Provinces, natural examples of rheoplastic structures are common at the interface between structureless sandstone and decimetre to metre-scale bodies of siltstone that have obviously undergone post-depositional movement, probably during earthquakes. The field relationships of the mud bodies show that they cannot have been sedimentary clasts and could not, therefore, have been fluted by hydraulic action on a river bed. Rheoplasis provides a plausible alternative mechanism for the formation of these structures.

The origin, interpretation and signifiance of sole marks in general may need review in the light of these findings.

\section{ACKNOWLEDGEMENTS}

This work was conducted while A.G. Plint was in receipt of a UNB Post-doctoral fellowship, which is acknowledged with thanks. H.W. van de Poll wishes to acknowledge NSERC operating grant No. A9033. We thank Prof. E.K. Walton and $\mathrm{Dr}$. P. McL. Duff for constructive criticism, and Joyce Ley for typing the various drafts of the manuscript.

ANKETELL, J.M. and DZULYNSKI, S. 1968. Transverse deformational patterns in unstable sediments. Annals of the Geological Society of Poland, 38, pp. 412-416.

ANKETELL, J.M., CEGLA, J. and DZULYNSKI, S. 1970. On the deformational structures in systems with reversed density gradients. Annals of the Geological Society of Poland, 40, pp. 3-30. 
BYERLY, P. 1942. Seismology. New York, Prentice Hall, Inc., 256p.

HANSEN, W.R. 1965. Effects of the Earthquake of March 27th, 1964 at Anchorage, Alaska. United States Geological Survey, Professional Paper 542-A, 68p.

KAWASUMI, H. 1968. (Ed.) General report on the Niigata Earthquake of 1964. Tokyo Electrical Engineering College Press, 550p.

MONROE, J.N. 1969. Slumping structures caused by organically derived gases in sediments. Science, 164, pp. 13941395.

ODE, H. 1966. Gravitational instability of a multi-layered system of high viscosity. Verhandelingen Koninklyke Nederlandse Akademie van Wetenschappen Afdeling, Natuurkunde, 24, 96p.

PLINT, A.G. and POLL, H.W. van de, 1982. Post-depositional mud migration structures in the Tynemouth Creek Formation; Lower Pennsylvanian, southern New Brunswick (Abs.). Maritime Sediments and Atlantic Geology, 18, p. 44.

POLL, H.W. van de and PATEL, I.M. 1980. Liquefaction and intrastratal flow phenomena in continental beds of the Boss Point Formation: Carboniferous, southeastern New Brunswick (Abs.). Geological Association of Canada, Mineralogical Association of Canada, Program with Abstracts, 5, Joint An- nuai Meeting, 19-21 May, 1980. Dalhousie University.

POLL, H.W. van de and PATEL, I.M. 1981. Flute casts and related structures on moulded silt injection surfaces in continental sandstone of the Boss Point Formation: southeastern New Brunswick, Canada. Maritime Sediments and Atlantic Geology, 17, pp. 1-22.

POLL, H.W. van de, PLINT, A.G. and PATEL, I.M. 1982. Physical diagenesis: a neglected aspect in the reconstruction of ancient sedimentary environments (Abs.). Maritime Sediments and Atlantic Geology, 18, p. 51.

REIMNITZ, E. and MARSHALL, N.F. 1965. Effects of the Alaska earthquake and tsunami on recent deltaic sediments. Journal of Geophysica1 Research, 70, pp. 2363-2376.

TUTHILL, S.J. and LAIRD, W. M. 1966. Geomorphic effects of the earthquake of March 27th, 1964 in the MartinBering Rivers area, Alaska. United States Geological Survey, Professional Paper, 543-B, 29p.

WALLER, R.M. 1968. Water-sediment Ejections. In The Great Alaska Earthquake of 1964, p. 97-116. Committee on the Alaska Earthquake of the division of earth sciences, National Research Council. Publication 1603, National Academy of Sciences, Washington, D.C. 441p. 